\title{
Analysis of the influence of position of welding materials on the FSW seams properties for three dissimilar aluminium alloy
}

\author{
Ana Bosneag ${ }^{1, *}$, Marius Adrian Constantin ${ }^{1}$, Eduard Nițu $^{2}$ and Monica Iordache $^{2}$ \\ ${ }^{1}$ University Politehnica of Bucharest, Machine Building Technology Department, Splaiul \\ Independenţei Street No. 313, Bucharest, Romania \\ ${ }^{2}$ University of Piteşti, Manufacturing and Industrial Management Department, Târgul din Vale Street \\ No.1, Pitești, Romania
}

\begin{abstract}
Friction Stir Welding, abbreviated FSW is a new and innovative welding process. This welding process is increasingly required, more than traditional arc welding, in industrial environment such us: aeronautics, shipbuilding, aerospace, automotive, railways, general fabrication, nuclear, military, robotics and computers. FSW, more than traditional arc welding, have a lot of advantages, such us the following: it uses a non-consumable tool, realise the welding process without melting the workpiece material, can be realised in all positions (no weld pool), results of good mechanical properties, can use dissimilar materials and have a low environmental impact. This paper presents the results of experimental investigation of friction stir welding joints to three dissimilar aluminium alloy AA2024, AA6061 and AA7075. For experimenting the value of the input process parameters, the rotation speed and advancing speed were kept the same and the position of plates was variable. The exit date recorded in the time of process and after this, will be compared between them and the influence of position of plate will be identified on the welding seams properties and the best position of plates for this process parameters and materials.
\end{abstract}

\section{Introduction}

The Friction Stir Welding technique, was invented for aluminium alloy by the Welding Institute - TWI, U.K., in 1991. In the last years, this innovative welding process, was used to join by welding a large range of materials, similar and dissimilar, such us the following: aluminium, cooper, magnesium, brass, titanium, steel [1], polymeric materials [2] and metal matrix composites materials [3]. The FSW process is a simple one, a rotating tool is pressed against the surface of two, or more, abutting or overlapping plates, then the tool start to perform a translation move along the welding seam [4]. The temperature raised in the process step is due to mechanical loads, to friction between the tool shoulder and work piece. As the temperature increases, the material softens and the coefficient of friction

\footnotetext{
*Corresponding author: ana.bosneag89@yahoo.com
} 
decreases. [5]. Applicability of this welding process was easily found for a lot of domain and industries. More than $50 \%$ of industries applicability is directed to transportation of which they can be listed: automotive industry, aeronautics industry, aerospace industry, railway industry. The rest of 50\% are splitter between: metal working, research and development, electronic industry, machinery and equipment and others [6]. Until now a lot of publication presented a study where this three aluminium alloys: AA2024, AA6061 and AA7075 were combined two by two with good results, such us:

-alloys AA6061 and AA7075 were welded with good results using tapered shape of pin [7], as well the square tool pin profile and hexagonal tool pin profile combined with rotation speed 1250 [rpm] and welding speed 110 [mm/min] leads to a good quality of welds [8]. Another study, with the same combination of alloys, shows a modification in the chemical composition for TMAZ and HAZ regions [9].

-alloys AA2024 and AA7075 were successful welded without defects with rotation speed 1200 [rpm] and welding speer $100 \mathrm{~mm} / \mathrm{min}$ and tool cylindrical [10] and corrosion behaviour for FSW welding of this two dissimilar aluminium alloy was good [11].

-alloys AA6061 and AA2024 were joined by FSW and was observed that the cylindrical threaded pin tool profile and squared pin tool profile are found to be the best [12].

This paper has the purpose to analyse the influence of aluminium alloy position in the welding system. This three aluminium alloy: AA2024, AA6061 and AA7075 will be weld together, in the same time, and from one experiment to another the parameters will be kept the same and the position of plates will be changed. After the welding process, the welding seams will be analysed in terms of: macro-hardness, macrostructure and microstructure.

\section{Experimental procedure}

\subsection{Welding process}

The three dissimilar aluminium alloy: AA2024, AA6061 and AA7075 were joined according the overlapping configuration, and all of this will be one at a time in upper position, in middle position and in lower position. The welding plate dimensions are 140 $\mathrm{mm} \times 250 \mathrm{~mm}$ and thickness $2 \mathrm{~mm}$. On the welding machine, this package was fixed with a special device. FSW process is presented in Figure 1. The used welding tool is a cylindrical one, Figure 2, with pin shape threaded M6, high of pin equal with $5.3 \mathrm{~mm}$, diameter of the shoulder equal to $\phi 22 \mathrm{~mm}$ and material carbide of sintered tungsten $(\mathrm{P} 20+\mathrm{S})$.
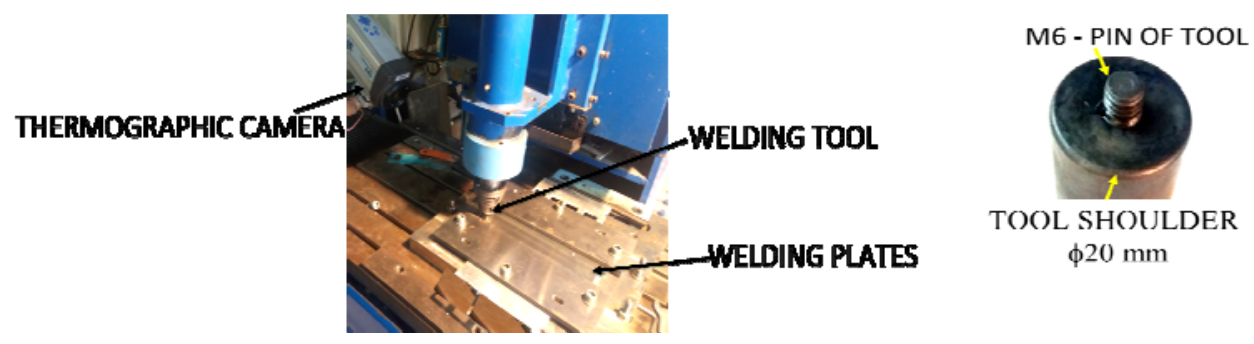

Fig. 1. FSW process.

Fig. 2. Welding tool.

\subsection{Base materials}

The effective chemical composition and mechanical characteristics of the three different aluminium alloy: AA2024, AA6061 and AA7075, are listed in Table 1. 
Table 1. Chemical composition and mechanical characteristics of AA2024, AA6061 and AA7075.

\begin{tabular}{|c|c|c|c|c|c|c|c|c|c|c|c|c|}
\hline \multicolumn{7}{|c|}{ Chemical composition [ weight \%] } & \multicolumn{3}{|c|}{ Mechanical characteristics } \\
\hline & $\mathrm{Si}$ & $\mathrm{Fe}$ & $\mathrm{Cu}$ & $\mathrm{Mn}$ & $\mathrm{Mg}$ & $\mathrm{Cr}$ & $\mathrm{Zn}$ & $\mathrm{Ti}$ & $\mathrm{Ti}+\mathrm{Zr}$ & $\mathrm{UTS}[\mathrm{MPa}]$ & YS [MPa] & Elongation [\%] \\
\hline AA2024 & 0.10 & 0.1 & 4.4 & 0.47 & 1.5 & 0.01 & 0.14 & 0.04 & 0.05 & 464 to 466 & 344 to 348 & 17 to 18 \\
\hline AA6061 & 0.74 & 0.4 & 0.2 & 0.14 & 0.9 & 0.18 & 0.09 & 0.05 & - & 317 to 319 & 286 to 290 & 10 to 12 \\
\hline AA7075 & 0.05 & 0.1 & 1.6 & 0.05 & 2.7 & 0.19 & 5.80 & 0.05 & 0.01 & 593 to 594 & 531 to 532 & 11 to 12 \\
\hline
\end{tabular}

\subsection{Experimental plan}

The input parameters in FSW process are the welding speed [ $\mathrm{mm} / \mathrm{min}]$ and the rotation speed [rpm]. In the actual paper six experiments with the same values for input parameters and with a variation for position of plates one of the others, Table 2, are analysed.

Table 2. Experimental plan for FSW.

\begin{tabular}{|c|c|c|c|c|c|c|}
\hline Code of experiment & 1.5 & 1.6 & 2.5 & 2.6 & 3.5 & 3.6 \\
\hline Position of materials & \multicolumn{2}{|c|}{$\begin{array}{l}\text { AA2024 - upper } \\
\text { AA6061 - middle } \\
\text { AA7075 - lower }\end{array}$} & \multicolumn{2}{|c|}{$\begin{array}{l}\text { AA6061 - upper } \\
\text { AA7075 - middle } \\
\text { AA2024 - lower }\end{array}$} & \multicolumn{2}{|c|}{$\begin{array}{l}\text { AA7075 - upper } \\
\text { AA2024 - middle } \\
\text { AA6061 - lower }\end{array}$} \\
\hline Welding speed $[\mathrm{mm} / \mathrm{min}]$ & \multicolumn{6}{|c|}{120} \\
\hline Rotation speed [rpm] & \multicolumn{6}{|c|}{1000} \\
\hline
\end{tabular}

\section{Results and discussions}

\subsection{Temperature evolution analysis}

In FSW process, the temperature was measured with a thermographic infrared camera, of FLIR A40M type, on the middle of the welding joint, behind the welding tool. The temperature evolution, is presented in Figure3. On the left side of the vertical line, it is represented the evolution of temperature in penetration and preheating step. On the right side, it is represented the evolution of temperature in welding along the welding seam.

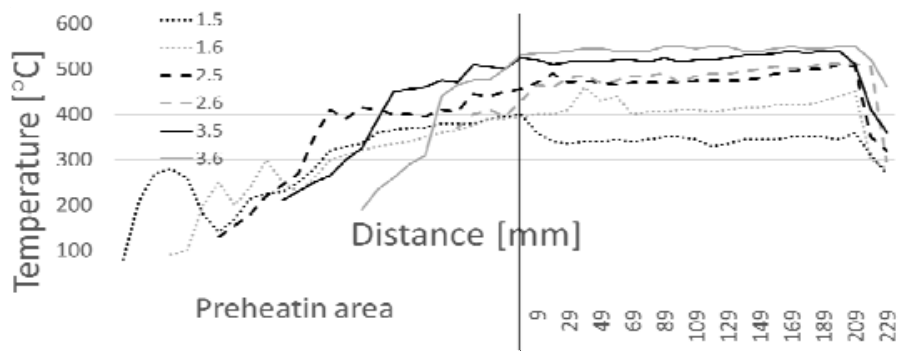

Fig. 3. Evolution of temperature in process time for all experiments.
Table 3. Min and Max temperature during welding.

\begin{tabular}{|c|c|c|}
\hline Exp. & $\operatorname{Min}\left[{ }^{\circ} \mathrm{C}\right]$ & $\operatorname{Max}\left[{ }^{\circ} \mathrm{C}\right]$ \\
\hline 1.5 & 270 & 360 \\
\hline 1.6 & 280 & 460 \\
\hline 2.5 & 320 & 510 \\
\hline 2.6 & 295 & 510 \\
\hline 3.5 & 360 & 540 \\
\hline 3.6 & 460 & 550 \\
\hline
\end{tabular}

In Table 3, is represented the minimum and the maximum temperature in the welding steps for all six experiments. The lower minimum temperature as well as the lower maximum temperature are used for experiments 1 (1.5 and 1.6), where the position of the materials are AA2024 upper, AA6061 middle and AA7075 lower position. The biggest minimum temperature and the biggest maximum temperature are for experiments 3 (3.5 and 3.6), where the position of the materials are: AA7075 upper, AA2024 middle and AA6061 lower position. The difference between minimum values and maximum values are the same, 
$190^{\circ} \mathrm{C}$. The difference between this experiments shows an influence of position of materials in the welding seam. For example, when material AA7075 was in a lower position, the temperature have the lower value and when the same material has been moved in the upper position, the temperature had the biggest value.

\subsection{Micro-hardness evolution analysis}

In this experimental study, the micro-hardness value was measured in one position, on welding seam, for all six experiments, this position was define at approximate $230 \mathrm{~mm}$ to the start weld. Measurement have been made perpendicular on the tool movement direction, along the welding elements on three lines of depth, one for each material, at $1 \mathrm{~mm}, 3 \mathrm{~mm}$ and $5 \mathrm{~mm}$ from the weld surface. On each line, micro-hardness was measured in 11 points, on $10 \mathrm{~mm}$ along the welding centre. In lower graphics (Figures 4-9) and tables (Tables 4-6) are represented the micro-hardness evolutions for all experiments and the average of microhardness for all three materials. The first difference between this experiments is represented by the missing value for the experiments 2 (2.5 and 2.6) and experiments 3 (3.5 and 3.6). This absence is explained by the presence of defects in welding seams. The defects rate is presented, for all four experiments, in materials AA2024 and less in AA7075, this defects occur in experiments where this two materials are next to each other. For experiments 1 (1.5 and 1.6), the graphics are completed because the defect rate is lower than for the other experiments.

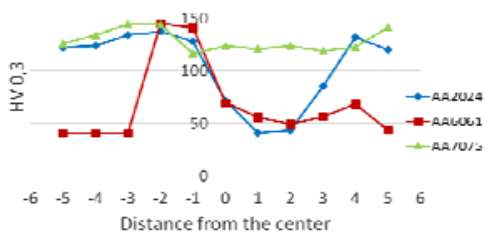

Fig. 4. Micro-hardness for 1.5.

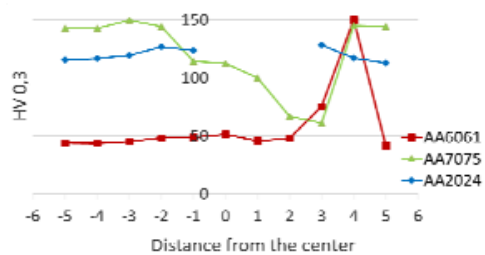

Fig. 6. Micro-hardness for 2.5 .

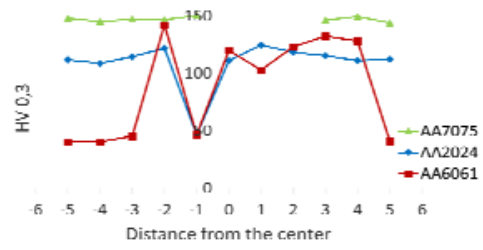

Fig. 8. Micro-hardness for 3.5.

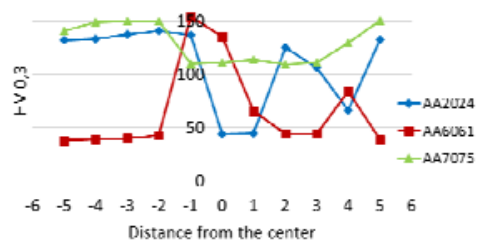

Fig. 5. Micro-hardness for 1.6.

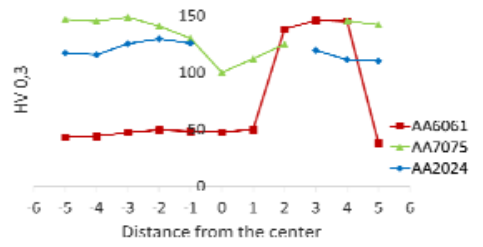

Fig. 7. Micro-hardness for 2.6.

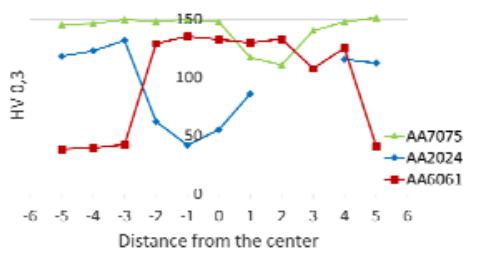

Fig. 9. Micro-hardness for 3.6.
Table 4. Average micro-hardness for experiments 1 .

\begin{tabular}{|c|c|}
\hline 1.5/ 1.6 & Average \\
\hline AA2024 & 106.3 \\
\hline AA6061 & 67.1 \\
\hline AA7075 & 129.2 \\
\hline
\end{tabular}

Table 5. Average micro-hardness for experiments 2 .

\begin{tabular}{|c|c|}
\hline 2.5/2.6 & Average \\
\hline AA6061 & 65.5 \\
\hline AA7075 & 127.0 \\
\hline AA2024 & 119.8 \\
\hline
\end{tabular}

Table 6. Average micro-hardness for experiments 3 .

\begin{tabular}{|l|c|}
\hline 3.5/ 3.6 & Average \\
\hline AA7075 & 144.2 \\
\hline AA2024 & 101.3 \\
\hline AA6061 & 91.57 \\
\hline
\end{tabular}

Spread of micro-hardness value can be compared as well. For experiments 1 (1.5 and 1.6), the spread is in advancing side, from $0 \mathrm{~mm}$ to $5 \mathrm{~mm}$, for experiments 2 (2.5 and 2.6) the spread is similar, in advancing side from $0 \mathrm{~mm}$ to $5 \mathrm{~mm}$ and for experiments 3 (3.5 and 3.6), the spread is different - this includes both, advancing and retracting, side from $3 \mathrm{~mm}$ to $5 \mathrm{~mm}$. 


\subsection{Macrostructure evolution analysis}

The macrostructure evolution was captured in the same position, on welding seams, with micro-hardness, at $230 \mathrm{~mm}$ to the start weld. All captures are presented in Fig 10-12. In all cases, we remark defects such us: tunnels, pore and lack or fusion, in welding seams.

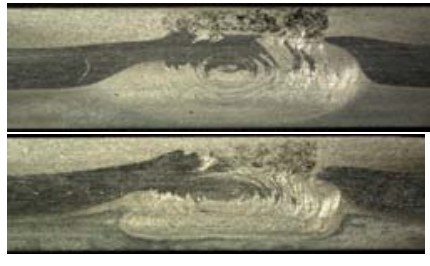

Fig. 10. Macrostructure for experiments 1.5 and 1.6.

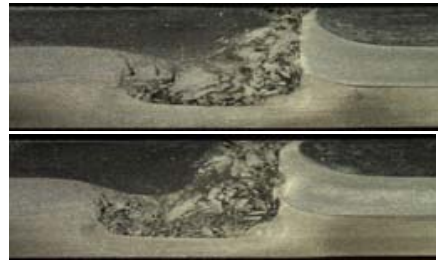

Fig. 11. Macrostructure for experiments 2.5 and 2.6 .

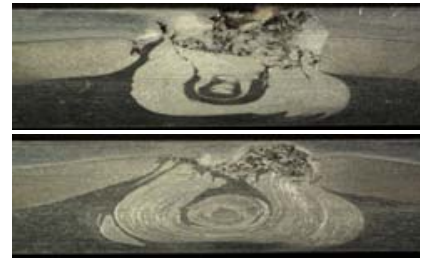

Fig. 12. Macrostructure for experiments 3.5 and 3.6 .

The first experiments, Figure 10 represents the less defect rate, this was demonstrated and at micro-hardness analysis. For this, the defects are concentrated in upper material, AA2024, as well the weld nugget has a good aspect and is better defined. The second experiments, presented in Fig 11, has the biggest defect rate and lack of fusion, spread in all three materials, predominant in weld nugget. The last experiments, the $3^{\text {rd }}$ one, presents some defects such us: tunnels, pore and lack of fusion, more for experiment 3.5, in upper material (AA7075) and between upper and middle materials (AA2024). In this experiment, the weld nugget is the best defined and the mix between materials can be easily noticed.

The differences between the macrostructure evolutions can be explained through the compatibility among this three aluminium alloy.

\subsection{Microstructure evolution analysis}

The microstructure was analysed for experiment 1.6 and 3.6 because this one has the better quality. The magnification used to capture these images are $10 \mathrm{X}$ and the scale $100 \mu \mathrm{m}$.

Defects, in the welding seams, was recording for bought this two experiments, in experiment 1.6 was measured pore with length to $206 \mu \mathrm{m}$, Fig 13 and surface with small crazing in AA6061, Fig 14. In 3.6, it is captured the surfaces with the major defects, Fig 15, and surface with the crazing between AA7075 and AA2025 Figure 15.

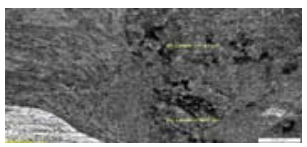

Fig. 13. Defects (1.6).

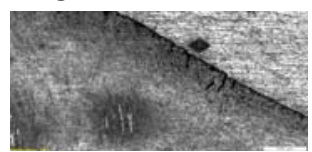

Fig. 14. Crazing (1.6).

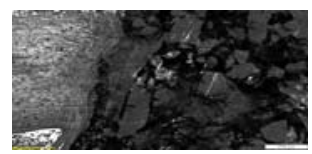

Fig. 15. Defects (3.6).

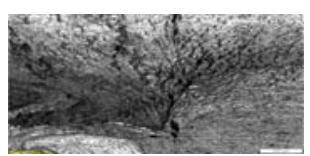

Fig. 16. Crazing (3.6).

A common characteristic between this two experiments is represented by the weld zone (WZ), this zone presented the good blend of materials and a good flow of this. Some images with weld zone are presented in Fig 17 and Fig 18.

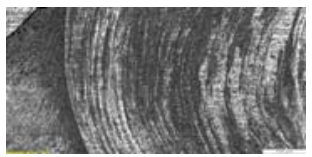

Fig. 17. Weld zone for experiment 1.6.
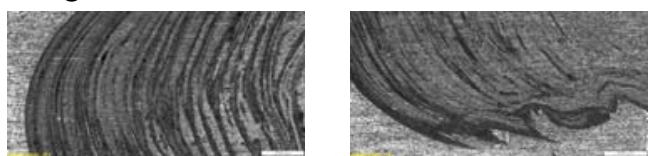

Fig. 18. Weld zone for experiment 3.6.

In conclusion, it is obvious that between this three aluminium alloys does not exist a metallurgical process during welding, and regardless of the material position in welding system, does not produce a piece without defects with the parameter used. 


\section{Conclusions}

Based on the researchers results the analysis presented in this paper, the following main conclusions are drawn:

1. This paper did not achieve the best result of FSW, but it is a first step for future researches which involves joining three dissimilar materials. Until now, the FSW for three dissimilar materials, was not exploited and have a big potential for industrial applications.

2. Position of the welding plates influences the welding temperature in process time. The welding temperature for AA7075 alloy increased when was move in upper position.

3. Micro-hardness has good results for all three situation, but the best average of it was achieve for the $3^{\text {rd }}$ experiments and the best spread of micro-hardness value was achieved, as well, for experiments 3 (3.5 and 3.6).

4. Macrostructure analysis show a differences between all three experiments, and certify the importance of material position for quality welding joint.

5. Microstructure analysis confirm the presence of defects in all experiments, but the best results was achieve for experiments 1 (1.5 and 1.6), when material AA2024 was in upper position and AA7075 was in lower position.

6 . The proper selection of tool pin profile and parameters will give the better results. In the future work, this study will be extended to a large set of parameters and more analysis of them.

The work was realised with the support of the National R\&D Institute for Welding and Material Testing, ISIM Timişoara.

\section{References}

1. C.M.A. Leitao, Universidade de Coimbra, (2013)

2. Z. Kiss, T. Czigany, Mech. Eng. 51, 15-18 (2007)

3. G. Minak, L. Ceschini, I. Boromei, M. Ponte, Int. J. of Fatigue 32, 218-226 (2010)

4. A. Mishra, SRM Institute of Science and Technology, (2018)

5. A. Mishra, K. Sharma, J. Adv. Res. Mech. Engi. Tech 4, 4 (2017)

6. V.M. Magalhaes, C Leitao, D.M. Rodrigues, Science and Technology of Welding and Joining, (2017)

7. R. Hariharan, R.J.G.R. Nimal, Middle-East Journal of Scientific Research 20, 5, 601605 (2014)

8. H.M.A. Kumar, V.V. Ramana, Int. J. of Latest Trends in Engineering and Technology 8, 3, 121-126 (2017)

9. M.M. Hasan, M. Ishak, M.R.M. Rejab, ICMER2017 257 (2017)

10. H.M.A Kumar, V.V. Ramana, S.P. Shanmuganathan, Middle-East Journal of Scientific Research 25, 5, 1009-1014 (2017)

11. M.K. Abbass, R.A. Anaee, M.M. Jabar, IJS Archives of Mechanics and Machine Engineering 2, 5, 1-15 (2016)

12. P. Sadeesh, M.K. Venkatesh, V. Rajkumar, P. Avinash, N. Arivazhagan, K.R. Devendranath, S. Narayanan, Procedia Engineering 75, 145-149 (2014) 